ORIGINAL ARTICLE

\title{
PERCEPTIONS OF DHAKA CITY RETAILERS ON USER CHOICE OF SELF-MONITORING BLOOD GLUCOSE DEVICES
}

\author{
J Nayeem $^{1}$, SM Kamaluddin ${ }^{1}$, HA Chowdhury ${ }^{2}$, L Ali $^{3}$ \\ ${ }^{1}$ Department of Applied Laboratory Sciences, Bangladesh University of Health Sciences (BUHS), Dhaka; \\ ${ }^{2}$ Department of Biostatistics, Bangladesh University of Health Sciences (BUHS), Dhaka; ${ }^{3}$ Department of \\ Biochemistry and Cell Biology, Bangladesh University of Health Sciences (BUHS), Dhaka
}

ABSTRACT

Self-Monitoring Blood Glucose (SMBG) Devices are now thought to be an integral component in the prevention and management of diabetes mellitus which is increasingly becoming a major health and economic burden particularly in developing countries. The marketing of these Devices, however, are still not well regulated in most of the countries and this, in turn, may lead to more harm than good to the patients who are using these devices. Retailers are the most important contact points who create the interface among the Manufacturers, Professionals and Consumers for popularization of health related devices. In this study, the Users' Choice of SMBG Devices and its determinants, as reflected in the views of the Sales Persons (in a retail shop) in Dhaka City of Bangladesh, have been explored. Twenty Sales Persons from 20 Retail Shops, purposively selected from among major Dhaka City markets where these devices are commonly sold, were individually interviewed using a pretested Interviewer administered Questionnaire. The instrument consisted of six questions covering the Users' preference regarding quality vs cost and also regarding the guidance and motives for purchasing specific items. The results were analyzed by descriptive statistics. It was found that $90 \%$ of the consumers are dependent on the suggestions of the Sales Persons regarding the choice of devices. In $80 \%$ of the subjects the cost of the System was found to be the determining factor regarding the choice of a meter. Only among $20 \%$ subjects, quality played any role in the choice. In conclusion, the choice of specific SMBG devices in Dhaka City is overwhelmingly influenced by Retailers (who, in most cases are not even qualified Pharmacists or Pharmacy Assistants) and, except in few cases; Users are not concerned with quality. Price, particularly the price of the strip, is the dominant factor on Users' choice of SMBG Devices.

Key Words: SMBG Devices; Blood glucose Monitoring; User Choice; SMBG Retailer's Views

\section{Introduction}

Self-monitoring of blood glucose (SMBG) is widely recognized as an integral component of adequate diabetes management that enables patients to control their blood glucose (BG) levels effectively ${ }^{1}$. Several studies have demonstrated the importance of tight blood glucose control for diabetic patients, especially when applying intensive insulin regimens, to avoid occurrence of hyperglycemia or hypoglycemia and their respective long-term consequences ${ }^{2}$. Early published reports indicated benefits for the patients with improved metabolic control when blood glucose (BG) was measured at home ${ }^{3-5}$. The clinical benefits of SMBG in type 1 diabetic patients are widely accepted6 and in type 2 
diabetes patients, clinical, epidemiological, and economic evidence supporting SMBG is accumulating steadily ${ }^{7-12}$. Guidelines from the American Diabetes Association ${ }^{13}$ and the International Diabetes Federation ${ }^{14}$ recommend the use of SMBG as an integral component of adequate diabetes management that enables patients to control their BG levels effectively ${ }^{15}$.

The important role of accurate BG measurement in the context of a pandemically increasing number of diabetic cases worldwide has resulted in an increasing number of BG monitoring (BGM) systems ${ }^{16}$ which have been developed and launched globally. A multitude of SMBG systems are available and an increasing number of new systems are being introduced every year. Accordingly, both health care providers and patients need guidance to choose between systems at affordable price ranges ${ }^{17}$. Those systems include well-established as well as completely new ones, eg. Systems providing new technologies. To ensure appropriate function of the devices, standardization tests have been introduced for quality assurance purposes, which also allow for comparative testing of BGM devices. In the developed world, a few clinical trials have been conducted ${ }^{18-20}$ to test compliance with accuracy requirements stipulated by the International Organization for Standardization (ISO) 15197: $2003^{21}$.

In Bangladesh, health care professionals and diabetic patients are not largely aware about the vital importance of SMBG and thus the device are still not optimally popularized in our country. In Bangladesh diabetes and related cardiovascular disorder are rapidly growing health problems ${ }^{22}$ and a fairly large number of SMBG systems are available in this market. However, the actual number of those in use is unknown as there are frequent fluxes or turnover in the market. In reality there are many issues that manipulate Users to purchase the devices. Sales persons of Retail shops most of whom are not even qualified Pharmacists are central contact persons who create the interface among the Manufacturers, Professionals, and Consumers.

No study has so far been reported from Bangladesh to find out the actual factors or criteria which the Consumers or Users usually consider in purchasing or selecting the device. Under this context, the present study was undertaken to explore the views of major retailers of Dhaka city on the Users' choice regarding SMBG Devices.

\section{Materials and Methods}

This was a cross sectional study which was performed in the major markets of Dhaka city where these devices are commonly sold. Twenty Sales Persons from 20 purposively selected retail shops were individually interviewed using a pretested Interviewer administered Questionnaire. The survey instrument consisted of six questions covering questions evaluating perceptions of Retailer on Users' choice regarding SMBG. The following points were covered in the Questionnaire: Tracking the Advisor (Sales Persons in Retail shops, Self, Provider and others) in whose suggestion a specific device was chosen, Preferred price range for the Device (BDT), Any question by the Consumer regarding accuracy, and User priority regarding quality vs price (the price of devices as well as strips).

Informed consent was obtained from individual participants after detailed explanation of the nature, purpose, and procedures used. Retailers were informed about their right to withdraw from the study at any stage. Ethical approval was obtained from the 'Ethical Review Committee of the Bangladesh University of Health Sciences'. The results were analyzed by descriptive statistics.

\section{Results}

As shown in Table 1, 90\% of the Consumers were found to be dependent on the suggestions of the Sales Persons regarding the choice of devices. Among the Consumers $35 \%$ and $30 \%$ chose 
SMBG Devices in the price range of BDT 700 1000 and BDT 1000-1200, respectively. Among the Consumers, $75 \%$ did not bother about the quality of the SMBG Devices. The prices of the SMBG Devices were found to be the main factor among $80 \%$ of the Consumers behind the choice (Table-1). Further analysis of the price issue showed that the, cost of the strips were the main determining factors regarding the choice of SMBG Devices among $80 \%$ Consumers (figure 1).

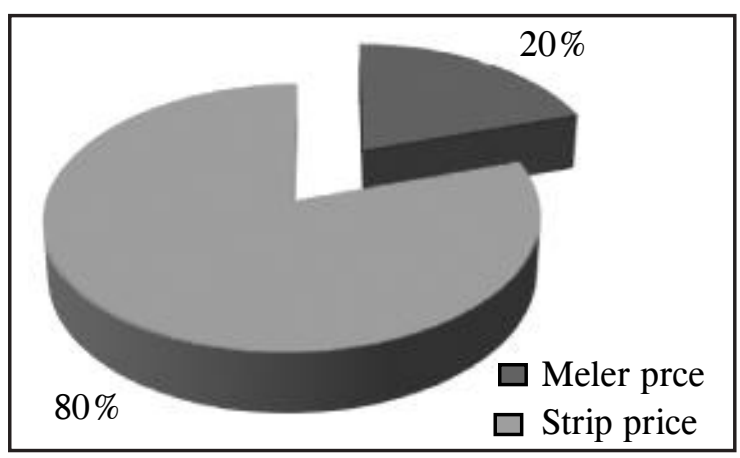

Figure-1: Concern for meter/strip price regarding in choice SMBG Devices

Table-I: Retailers' perceptions on Users' choice of SMBG devices

\begin{tabular}{lcc}
\hline Variables & Number of respondents & Percentage \\
\hline Specific Device advised by & & \\
Sales Persons in Retail shops & 18 & 90 \\
Provider and others & 1 & 5 \\
Self & 1 & 5 \\
Preferred price range for the Device (BDT) & \\
$700-1000$ & 7 & 35 \\
$1000-1200$ & 6 & 30 \\
$1200-1800$ & 4 & 20 \\
$1800-2500$ & 3 & 15 \\
Any question by the Consumer regarding accuracy & \\
No & 15 & 75 \\
Yes & 5 & 25 \\
User priority regarding quality vs price & \\
Quality & 4 & 20 \\
Price & 16 & 80 \\
\hline
\end{tabular}

Results are expressed as number and percentages

\section{Discussion}

Blood glucose monitoring, an integral part of standard diabetes care ${ }^{23}$, often shows significant errors that are often poorly understood by patients and providers ${ }^{24}$. With large number of devices being available in the market, it is very difficult for health care providers to assess the relative accuracy of various blood glucose monitoring systems ${ }^{25}$. It is important to explore the motivating factor behind Users' Choice of SMBG Devices. In Dhaka City of Bangladesh, the Retailers in few major markets well thought to be the most appropriate persons who can deliver some information on the marketing issues. The survey revealed that cost rather than quality is the main factor which motivates the consumers to buy specific SMBG Devices. It appears that choice of the SMBG Device by users are almost completely at the mercy of the Sales Persons of the Retail Shops who themselves are, in most of the cases, not properly qualified and in many cases guided by ill motives. The data also indicate that, except in few cases, the Users do not bother at all regarding quality issues; they are only concerned with price, particularly price of the strips. This is an alarming finding and the blame should not go only to the Users or Retailers alone. In fact, education is the most neglected part of diabetes management in countries like Bangladesh and the present findings suggest that the patients are not educated properly regarding the importance of use as well as quality of SMBG Devices.

\section{Conclusion}

It can be concluded that, the Dhaka City Consumers are almost fully dependent on sales Persons in retail shops regarding the choice of SMBG Devices, and cost (particularly strip cost) rather than quality is the predominant factor in choosing specific systems. 
J Nayeem, SM Kamaluddin, HA Chowdhury et al

\section{Acknowledgements}

We gratefully acknowledge the contribution of all the Retailers and Sales Persons of the retail shops for their help and Bangladesh University of Health Sciences (BUHS) for financial support.

\section{Conflict of Interest}

The author report no relationship or financial interest with any entity that would pose a conflict of interest with the subject matter of this article

\section{References}

1. Blonde L, Karter AJ. Current evidence regarding the value of self- monitored blood glucose testing. Am J Med 2005; 118: 20S-6S.

2. The Diabetes Control and Complications Research Group. The effect of intensive treatment of diabetes on the development and progression of long-term complications in insulin-dependent diabetes mellitus. N Engl J Med 1993; 329: 977-986.

3. Walford S, Gale EAM, Allison SP, Tattersall RB. Self-monitoring of blood-glucose: Improvement of diabetic control. Lancet 1978; 1: $732-5$.

4. So"nksen PH, Judd SL, Lowy C. Home monitoring of blood-glucose. Lancet 1978; 1: 729-32.

5. Cohen M, Zimmet P. Self-monitoring of blood glucose levels in non-insulin-dependent diabetes mellitus. Med J Aust 1983; 2: 377-80.

6. Blonde L, Karter AJ. Current evidence regarding the value of self-monitored blood glucose testing. Am J Med 2005; 118(1): 20-26.

7. Welschen LM, Bloemendal E, Nijpels G, Dekker JM, Heine RJ, Stalman WA, Bouter LM. Selfmonitoring of blood glucose in patients with type 2 diabetes who are not using insulin: a systematic review. Diabetes Care 2005; 28: 1510-1517.

8. Sarol JN, Nicodemus NA, Tan KM, Grava MB. Self-monitoring of blood glucose as part of a multi-component therapy among non-insulin requiring type 2 diabetes patients: a metaanalysis (1966-2004). Curr Med Res Opin 2005; 21: 173-183.

9. Jansen JP. Self-monitoring of glucose in type 2 diabetes mellitus: a Bayesian meta-analysis of direct and indirect comparisons. Curr Med Res Opin 2006; 22: 671-681.

10. Mc Geoch G, Moore RA. Self-monitoring of blood glucose in type-2 diabetes: what is the evidence? Diabetes Metab Res Rev 2007; 23: 423-440.

11. Palmer AJ, Dinneen S, Gavin JR, III, Gray A, Herman WH, Karter AJ. Cost-utility analysis in a UK setting of selfmonitoring of blood glucose in patients with type 2 diabetes. Curr Med Res Opin 2006; 22: 861-872.

12. Schnell O, Hummel M, Weber C. Economic and clinical aspects of diabetes regarding selfmonitoring of blood glucose. Diabetes Technol Ther 2008; 10(1): 72-81.

13. American Diabetes Association. Standards of medical care in diabetes-2009. Diabetes Care 2009; 32(1): 13-61.

14. IDF Clinical Guidelines Task Force. Global Guideline for Type 2 Diabetes. Brussels: Brussels. Inter Diabet Fed, 2005.

15. Blonde L, Karter AJ. Current evidence regarding the value of self- monitored blood glucose testing. Am J Med 2005; 118: 20-6.

16. IDF Clinical Guidelines Task Force. Global Guideline for Type 2 Diabetes: recommendations for standard, comprehensive, and minimal care. Diabet Med. 2006; 23: 579-93.

17. Rao A, Wiley M, Iyengar S, Nadeau D, Carnevale J. Individuals achieve more accurate results with meters that are codeless and employ dynamic electrochemistry. J Diabetes Sci Technol 2010; 4: 14550. 
18. Kristensen GB, Monsen G, Skeie S, Sandberg S. Standardized evaluation of nine instruments for self-monitoring of blood glucose. Diabetes Technol Ther 2008; 10: 467-477.

19. Freckmann G, Baumstark A, Jendrike N, Zschornack E, Kocher S, Tshiananga J, Heister F, Haug C. System accuracy evaluation of 27 blood glucose monitoring systems according to DIN EN ISO 15197. Diabetes Technol Ther 2010; 12: 221-231.

20. Kuo CY, Hsu CT, Ho CS, Su TE, Wu MH, Wang CJ. Accuracy and precision evaluation of seven self-monitoring blood glucose systems. Diabetes Technol Ther 2011; 13: 596-600.

21. ISO 15197: 2003: In Vitro Diagnostic Test Systems-Requirements for Blood-Glucose Monitoring Systems for Self-Testing in Managing Diabetes Mellitus. Geneva: World Health Organization, 2003.
22. Nazmus S, Juliann S, Tahmeed A, Masuma AK, Mark R C. Cardiovascular diseases and Type 2 Diabetes in Bangladesh: A systematic review and meta-analysis of studies between 1995 and 2010. BMC Public Health 2012; 12: 434.

23. Bergenstal RM, Gavin JR III, Global Consensus Conference on Glucose Monitoring Panel. The role of self-monitoring of blood glucose in the care of people with diabetes: report of a global consensus conference. Am J Med 2005; 118 (Suppl 9A): 1S-6S.

24. Hirsch IB, Bode BW, Childs BP, Close KL, Fisher WA, Gavin JR, Ginsberg BH, Raine $\mathrm{CH}$, Verderese CA. Self-monitoring of blood glucose (SMBG) in insulin- and non-insulinusing adults with diabetes: consensus recommendations for improving SMBG accuracy, utilization, and research. Diabetes Technol Ther 2008; 10(6): 419-39.

25. Barry HG. Factors Affecting Blood Glucose Monitoring: Sources of Errors in Measurement, J Diabetes Sci Technol 2009; 3: 4. 